\title{
Evidence for an Important Role of Glucagon in the Regulation of Hepatic Glucose Production in Normal Man
}

\author{
John E. Liljenquist, Gary L. Mueller, Alan D. Cherrington, Ulrich Keller, \\ Jean-Louis Chiasson, James M. Perry, William W. Lacy, and David Rabinowitz \\ From the Departments of Medicine and Physiology, Vanderbilt University School of Medicine, \\ Nashville, Tennessee 37232
}

\begin{abstract}
A B S T RA C T To investigate the role of glucagon in regulating hepatic glucose production in man, selective glucagon deficiency was produced in four normal men by infusing somatostatin $(0.9 \mathrm{mg} / \mathrm{h})$ and regular pork insulin $(150-\mu \mathrm{U} / \mathrm{kg}$ per $\mathrm{min})$ for $2 \mathrm{~h}$. Exogenous glucose was infused to maintain euglycemia. Arterial plasma glucagon levels fell by greater than $50 \%$ whereas plasma insulin levels were maintained in the range of $10-14 \mu \mathrm{U} / \mathrm{ml}$. In response to these hormonal changes, net splanchnic glucose production (NSGP) fell by $75 \%$ and remained suppressed for the duration of the study.

In contrast, when somatostatin alone was administered to normal men, resulting in combined insulin and glucagon deficiency (euglycemia again maintained), NSGP fell markedly but only transiently, reaching its nadir at $15 \mathrm{~min}$. Thereafter, NSGP rose progressively, reaching the basal rate at $105 \mathrm{~min}$.

These data indicate that the induction of selective glucagon deficiency in man (with basal insulin levels maintained) is associated with a marked and sustained fall in hepatic glucose production. We conclude, there-
\end{abstract}

Dr. Liljenquist is an Investigator of the Howard Hughes Medical Institute. Dr. Mueller is a United States Air Force Sponsored Fellow in Endocrinology. Dr. Keller is a Research Fellow of the Juvenile Diabetes Foundation. Dr. Cherrington is the recipient of the Solomon Berson Research and Career Development Award of the American Diabetes Association.

Received for publication 27 September 1976 and in revised form 28 October 1976.

The Journal of Clinical Investigation Volume 59 fore, that basal glucagon plays an important role in the maintenance of basal hepatic glucose production in normal man.

\section{INTRODUCTION}

Whereas a major role for insulin in the regulation of hepatic glucose production in vivo is now well established (1-3), historically, glucagon has been ascribed only a minor role in the regulation of this process (4). Glucagon, though long known to be a potent glycogenolytic agent (5), was felt to be important in preventing hypoglycemia after a protein meal $(4,6$, 7 ), but evidence that it regulated basal hepatic glucose production in man was not available.

Recently the availability of somatostatin (8) has focused new attention on glucagon and its role in regulating hepatic glucose production. By virtue of its ability to suppress endogenous insulin and glucagon secretion when administered systemically (9), somatostatin has provided a way to separate the role of glucagon from that of insulin in the regulation of this process.

Initial studies employing somatostatin in the baboon indicated that decreasing the circulating levels of insulin and glucagon resulted in a fall in the plasma glucose concentration (9). This fall has subsequently been shown in the dog to be secondary to a decline in hepatic glucose production $(10,11)$ specifically due to the lowering of circulating glucagon (11). 


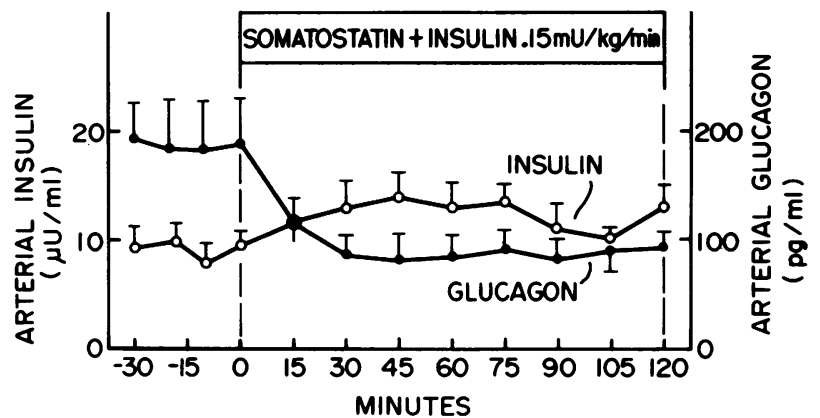

Figure 1 Effects of intravenous infusions of somatostatin $(0.9 \mathrm{mg} / \mathrm{h})$ and regular pork insulin on arterial insulin and glucagon levels in four normal men.

To date, no studies have been reported in man utilizing somatostatin to investigate the role of glucagon in regulating hepatic glucose production. We undertook the present study, therefore, to answer two questions: (a) what are the effects of inducing selective hypoglucagonemia (with maintenance of basal insulin levels) on splanchnic glucose production in man? and (b) does the concomitant induction of insulin deficiency modify the effects of acute glucagonopenia on this same process? To answer these questions, somatostatin was infused with and without a replacement insulin infusion to normal men who had undergone hepatic vein catheterization.

\section{METHODS}

Eight healthy, nonobese men between the ages of 18 and 30 were studied. The mean body weight was $74.8 \mathrm{~kg}$ (range, 56.3-86.0 kg). Studies began between 12:00 noon and 2:00 p.m. after a $12-14$-h fast.

The subjects were all placed on a 200-g carbohydrate diet for 3 days before study. In the $24 \mathrm{~h}$ before study, each subject received a high protein $(150-200 \mathrm{~g})$, high carbohydrate $(300-350 \mathrm{~g})$ diet. The protocol for this study was reviewed and approved by the Vanderbilt University Clinical Investigations Committee. The nature, purpose, and possible risks of the procedures were fully explained to each subject before obtaining his voluntary consent.

Hepatic venous and brachial artery catheterization were performed as previously described (12). After a 30-min basal period, $0.9 \mathrm{mg} / \mathrm{h}$ somatostatin was infused intravenously for $2 \mathrm{~h}$ in both groups of four subjects. In the first group, $150 \mu \mathrm{U} / \mathrm{kg}$ per min regular pork insulin was infused concomitantly into a peripheral vein. In both groups, euglycemia was maintained during somatostatin infusion by intravenous glucose administered at a variable rate according to the technique of Andres et al. (13). This was done to avoid any stimulatory effects of hypoglycemia on hepatic glucose production. To determine hepatic blood flow, indocyanine green was infused throughout the study via a peripheral vein.

Cyclic somatostatin was kindly provided by Dr. Roger Guillemin, Chief, Neuroendocrinology Division, Salk Institute, La Jolla, Calif. For infusion, insulin and somatostatin were mixed in saline with human serum albumin $(2 \mathrm{ml}$ of $25 \%$ human serum albumin/100 ml of solution) to eliminate binding of the hormones to glassware. Human serum albumin was similarly added to the indocyanine green infusate to increase its stability.

Plasma glucose was measured in a Beckman Glucose Analyzer (Beckman Instruments, Inc., Fullerton, Calif.). Plasma glucose was converted to whole blood glucose concentration (14) by the formula: whole blood glucose concentration $=$ plasma glucose concentration (1-0.3 hematocrit). Immunoreactive glucagon was assayed with the $30 \mathrm{~K}$ antiserum of Aguilar-Parada et al. (15). Immunoreactive insulin was assayed by the Sephadex-bound (Pharmacia Fine Chemicals, Inc., Piscataway, N. J.) antibody procedure (16). The plasma concentrations of indocyanine green were determined in a Beckman spectrophotometer at $810 \mathrm{~nm}$ and hepatic blood flow was calculated according to the method of Leevy et al. (17). The statistical significance was determined by the Student's or paired $t$ test whenever applicable (18).

\section{RESULTS}

Infusion of somatostatin and insulin. In the first set of experiments, the infusion of somatostatin resulted in a sharp fall in the plasma glucagon level which remained suppressed at less than $50 \%$ of basal (Fig. 1). Plasma insulin levels, however, were maintained between 10 and $14 \mu \mathrm{U} / \mathrm{ml}$ by the insulin infusion. Thus, a state of selective glucagon deficiency was produced.

Table I displays estimated hepatic blood flow $(\mathrm{EHBF})^{1}$ and mean hepatic venous-arterial blood glu-

${ }^{1}$ Abbreviations used in this paper: EHBF, estimated hepatic blood flow; HV-A, hepatic venous-arterial; NSGP, net splanchnic glucose production.

TABLE I

Mean EHBF and HV-A Blood Glucose Differences during Infusion of Somatostatin and Regular Pork Insulin $(150 \mu U / k g / m i n)$ in Normal Man $(n=4)$

\begin{tabular}{|c|c|c|c|c|c|c|c|c|c|c|c|c|}
\hline $\operatorname{Min} . . . \ldots . .$. & -30 & -20 & -10 & $\mathbf{0}$ & 15 & 30 & 45 & 60 & 75 & 90 & 105 & 120 \\
\hline \multicolumn{13}{|c|}{ Mean EHBF, $\mathrm{ml} / \mathrm{min}$} \\
\hline Mean & 1,682 & 1,623 & 1,627 & 1,553 & 1,069 & 1,089 & 1,075 & 1,040 & 1,103 & 1,130 & 1,138 & 1,125 \\
\hline SE & 149 & 135 & 126 & 210 & 223 & 149 & 141 & 162 & 177 & 206 & 157 & 189 \\
\hline \multicolumn{13}{|c|}{ Mean HV-A blood glucose difference, $m g / d l$} \\
\hline Mean & 9.7 & 10.1 & 9.2 & 10.8 & 4.5 & 3.9 & 2.6 & 3.0 & 3.7 & 4.6 & 3.7 & 4.3 \\
\hline SE & 0.9 & 1.0 & 0.4 & 1.1 & 0.9 & 0.9 & 0.7 & 1.0 & 1.2 & 1.6 & 0.6 & 0.8 \\
\hline
\end{tabular}


cose differences before and during infusion of somatostatin and insulin. A significant fall in EHBF was observed. The hepatic venous-arterial (HV-A) blood glucose differences declined immediately after the somatostatin and insulin infusion was begun and remained suppressed throughout the entire study.

Fig. 2A shows that net splanchnic glucose production (NSGP) fell markedly during the administration of somatostatin and insulin and remained suppressed for the duration of the study. Despite this fall in NSGP, euglycemia was maintained (Fig. 2B) by the infusion of glucose at the mean rate shown in Fig. 2C.

Infusion of somatostatin alone. The administration of somatostatin alone resulted in marked suppression of circulating plasma insulin and glucagon concentrations (Fig. 3). Plasma insulin levels declined from $9.2 \pm 1.9$ to $1.8 \pm 1.2 \mu \mathrm{U} / \mathrm{ml}$ whereas the circulating glucagon concentrations fell by more than $50 \%$ as in the previous protocol. The levels of both hormones remained suppressed.

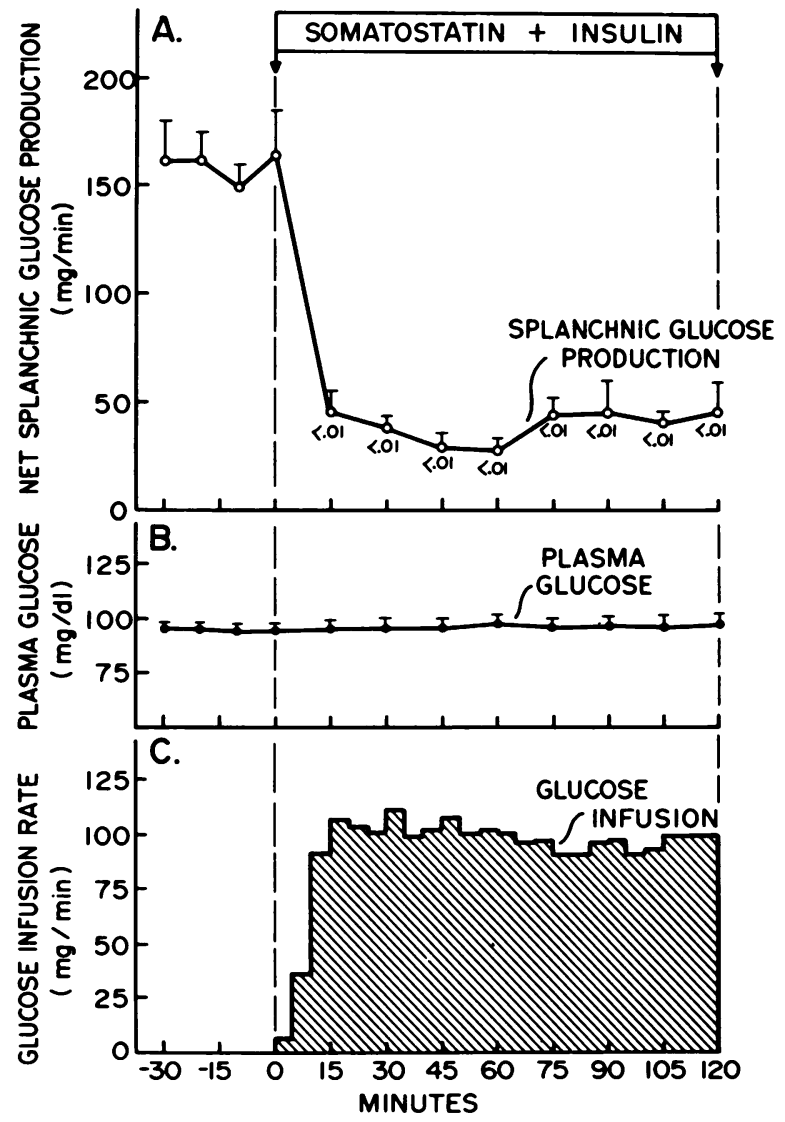

FIGURE 2 Effects of intravenous somatostatin $(0.9 \mathrm{mg} / \mathrm{h})$ and regular pork insulin on (A) net splanchnic glucose production and, (B) arterial plasma glucose concentration. (C) Depicts the rate of exogenous glucose infusion necessary to prevent hypoglycemia.

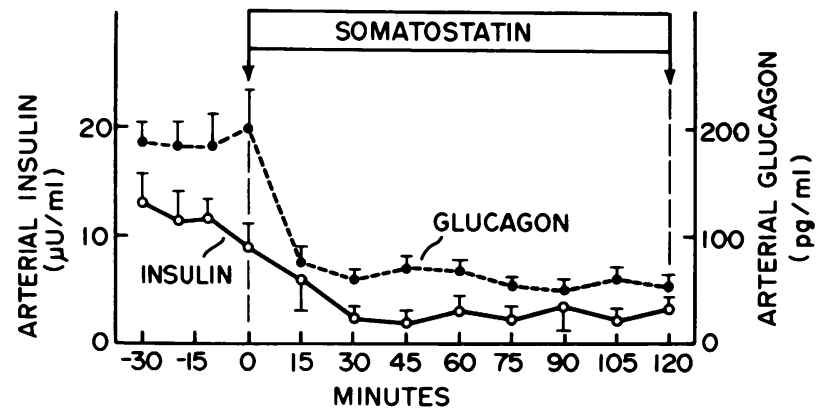

FIGURE 3 Effects of an intravenous infusion of somatostatin $(0.9 \mathrm{mg} / \mathrm{h})$ on arterial insulin and glucagon levels in four normal men.

The administration of somatostatin alone resulted in an immediate fall in EHBF which persisted for the duration of the study (Table II). HV-A blood glucose differences declined sharply by $15 \mathrm{~min}$, remained significantly suppressed at $30 \mathrm{~min}$, but then gradually returned to control levels by $90 \mathrm{~min}$.

The administration of somatostatin alone resulted in a rapid and highly significant, $74 \%$, decline in NSGP (Fig. 4A) which reached its nadir at $15 \mathrm{~min}$; thereafter, NSGP rose progressively. By $105 \mathrm{~min}$, despite continuing suppression of insulin and glucagon secretion, NSGP had returned to normal. Euglycemia (Fig. 4B) was maintained for the initial 60 min of the somatostatin infusion period by the concomitant infusion of glucose at the mean rate shown in Fig. 4C. As NSGP returned towards basal, the mean arterial glucose concentration rose (Fig. 4B), necessitating a diminution in the amount of glucose infused (Fig. 4C). In three of four subjects, the glucose infusion was completely stopped between times 50 and $70 \mathrm{~min}$ of the study but modest hyperglycemia nevertheless developed in all three subjects.

\section{DISCUSSION}

The intravenous infusion of somatostatin plus regular pork insulin at the rate of $150 \mu \mathrm{U} / \mathrm{kg}$ per min resulted in a state of selective glucagon deficiency. Circulating insulin levels were maintained in the range of $10-14 \mu \mathrm{U} / \mathrm{ml}$ and glucagon levels fell by greater than $50 \%$. Under these conditions, splanchnic glucose output declined by $75 \%$ and remained suppressed until the end of the 2-h study. These data indicate that the maintenance of basal hepatic glucose production in normal man is highly dependent on circulating glucagon and, furthermore, suggests that the lowering of circulating glucagon does not result in an evanescent but rather a sustained fall in hepatic glucose production. Both of these conclusions are further substantiated by recent results from our laboratory which showed that in dogs made glucagon deficient by con- 


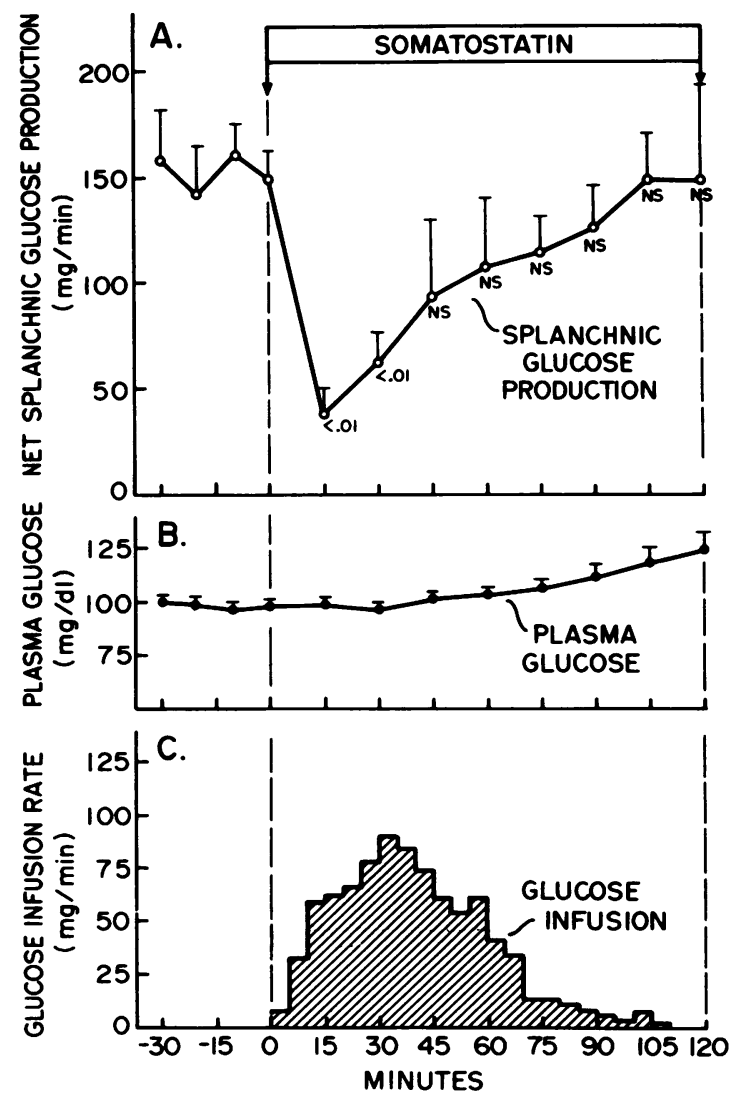

FIGURE 4 Effects of intravenous somatostatin $(0.9 \mathrm{mg} / \mathrm{h})$ on (A) net splanchnic glucose production and, (B) arterial plasma glucose concentration. (C) Depicts the rate of exogenous glucose infusion necessary to prevent hypoglycemia.

comitant infusion of insulin and somatostatin, glucose production fell and remained below normal over a 4.5$h$ period despite persisting hypoglycemia. ${ }^{2}$

The infusion of somatostatin alone resulted in combined insulin and glucagon deficiency. Under these conditions, NSGP fell markedly but only transiently and returned to normal within $2 \mathrm{~h}$. This is in contrast

${ }^{2}$ Cherrington, A. D., J. L. Chiasson, U. Keller, J. E. Liljenquist, P. Williams, and W. W. Lacy. Unpublished data. to the previous protocol in which maintenance of arterial insulin levels between 10 and $14 \mu \mathrm{U} / \mathrm{ml}$ resulted in a persistent decrease in NSGP. These data indicate that when glucagon is deficient, hepatic glucose production is profoundly sensitive to circulating levels of insulin which are approximately 50\% of those normally found in the portal vein (19).

The administration of somatostatin with or without concomitant insulin infusion resulted in significant decrements in EHBF of 34 and $25 \%$, respectively (Tables I and II). However, the mean HV-A blood glucose differences in these two protocols decreased even more dramatically (74 and $72 \%$, respectively). Because the calculation of NSGP is determined by both of these parameters, the fall in glucose production was primarily attributable to the decline in HV-A blood glucose difference. The rebound in the HV-A blood glucose difference, (3.5-fold over the minimum value), which occurred in the group receiving somatostatin alone also exceeded the concomitant statistically insignificant $13 \%$ rebound in blood flow which gradually occurred and was, therefore, again the primary determinant of the modification in NSGP.

It seems unlikely for two reasons that the decline in hepatic blood flow per se, rather than the changes in pancreatic hormone levels, could have produced the alterations noted in NSGP. First, we have performed similar studies using dogs in which somatostatin administration also resulted in a significant decrease in hepatic glucose production but did so in the total absence of any change in splanchnic blood flow (11). Secondly, were a drop in hepatic blood flow of this magnitude to have any effect on NSGP, it would be expected to increase rather than decrease it as suggested by studies of hepatic glucose production during periods of decreased hepatic blood flow (20).

The administration of somatostatin to baboons, dogs, and men has resulted in suppression of circulating insulin and glucagon levels and in the acute development of hypoglycemia secondary to a decrease in hepatic glucose production (9-11). The present study demonstrates, however, that the acute induction of

TABLE II

Mean EHBF and HV-A Blood Glucose Differences during Infusion of Somatostatin in Normal Man (n=4)

\begin{tabular}{|c|c|c|c|c|c|c|c|c|c|c|c|c|}
\hline Min........ & -30 & -20 & -10 & $\mathbf{0}$ & 15 & 30 & 45 & 60 & 75 & 90 & 105 & 120 \\
\hline \multicolumn{13}{|c|}{ Mean EHBF, $\mathrm{ml} / \mathrm{min}$} \\
\hline Mean & 1,780 & 1,801 & 1,676 & 1,700 & 1,311 & 1,495 & 1,415 & 1,394 & 1,430 & 1,514 & 1,537 & 1,527 \\
\hline SE & 212 & 196 & 78 & 239 & 184 & 157 & 158 & 104 & 156 & 171 & 124 & 114 \\
\hline \multicolumn{13}{|c|}{ Mean HV-A blood glucose difference, $m g / d l$} \\
\hline Mean & 8.9 & 7.4 & 9.4 & 9.2 & 2.9 & 3.8 & 6.0 & 7.2 & 8.1 & 8.8 & 9.7 & 10.2 \\
\hline SE & 1.0 & 0.8 & 1.0 & 1.2 & 1.0 & 0.7 & 2.1 & 2.1 & 1.4 & 2.1 & 1.0 & 3.8 \\
\hline
\end{tabular}


combined insulin and glucagon deficiency results in only a transient decrease in NSGP which effects only transient hypoglycemia. Indeed, a modest hyperglycemia of $117 \mathrm{mg} / \mathrm{dl}$ developed during the $2 \mathrm{nd} \mathrm{h}$ of the study. Similar results have been reported by Altszuler et al. (10) who noted that glucose production had returned to normal by $90 \mathrm{~min}$ in a third of their dogs receiving somatostatin. Thus, acute induction of combined insulin and glucagon deficiency is not associated with continuing suppression of glucose production.

The cause of the return of glucose production to normal despite continuing deficiency of insulin and glucagon is unknown. As euglycemia was maintained in the present study during somatostatin administration, the rise in NSGP towards the basal rate cannot be attributed to the counter-regulatory responses attendant upon hypoglycemia. In unpublished observations from human studies in our laboratory, we have noted that the inhibitory effects on NSGP of small increments in circulating insulin persist for approximately $30 \mathrm{~min}$ after cessation of the insulin infusion. ${ }^{3}$ The rise in NSGP towards basal appears to begin 15-30 min after initiation of somatostatin infusion (Fig. 4A) and may simply reflect the attenuation of the effects of basal insulin on the liver. Conversely, by infusing small amounts of insulin to maintain circulating arterial insulin levels in the range of $10-14 \mu \mathrm{U} / \mathrm{ml}$, far below normal portal venous insulin levels (19), NSGP remains suppressed and does not return to basal during somatostatin infusion. Another factor which may be responsible for this return of NSGP to normal is the residual immunoreactive glucagon which continues to circulate during somatostatin administration. Although it has been shown that this material probably does not represent pancreatic glucagon (21), nonetheless it is possible that it has some glycogenolytic activity which might be more prominent during states of insulinopenia.

Two sets of factors may have influenced the magnitude of the observed effects in this study. On the one hand, mean plasma glucagon levels were somewhat higher than we have observed in previous studies (12). These values were verified by independent assay in the laboratory of Dr. A. H. Rubenstein, University of Chicago, Pritzker School of Medicine. It is possible that the higher glucagon levels reflect the enrichment in protein of the subjects' diet on the day preceding the test. Basal NSGP and other metabolic indices, however, (e.g. individual amino acids, free fatty acids) were similar to those in previous studies. Nevertheless, in the presence of the higher basal glucagon levels, our studies may overestimate the

\footnotetext{
${ }^{3}$ Liljenquist, J. E., D. Rabinowitz, G. Mueller, A. D Cherrington, W. W. Lacy, and U. Keller. Unpublished data.
}

role of glucagon in the control of splanchnic glucose production. On the other hand, about $50 \%$ of basal glucagon immunoreactivity is not suppressed during somatostatin infusion. Should this material have any glycogenolytic or gluconeogenic activity, its continuing presence would lead us to underestimate the overall role of glucagon in regulating hepatic glucose production.

The interpretation of the data in this study is contingent upon the assumption that the extrapancreatic actions of somatostatin were not involved in the mediation of the biological responses observed. Somatostatin does not have direct effects on glucose flux in fat, muscle, or liver cells studies in vitro (22). Somatostatin, however, does inhibit the release of a variety of other hormones including growth hormone (8). Although this could have influenced the results of our study, it does not seem likely, because Gerich et al. (23) replaced growth hormone during somatostatin administration and noted no effect on the plasma glucose concentration. More definitive evidence emerges from our studies in the dog in which intraportal insulin and glucagon replacement during somatostatin administration results in maintenance of NSGP at basal rates (11). Our data, however, do not exclude a role for growth hormone in modifying the sensitivity of the liver to insulin.

The present study, therefore, presents data which indicate (a) that the induction of selective glucagon deficiency in man (with basal insulin levels maintained) is associated with a marked and sustained fall in hepatic glucose production, suggesting that basal glucagon plays an important role in the maintenance of hepatic glucose production in normal man; (b) that during periods of glucagon deficiency, glucose output by the liver is extremely sensitive to low levels of circulating insulin; and (c) that normal rates of hepatic glucose production are possible during glucagonopenia providing insulin is also deficient.

\section{ACKNOWLEDGMENTS}

The authors would like to acknowledge the excellent technical skills of Jill Hutton, Barbara Santoro, Phillip Williams, Patti Primm, and Leda Marshall. We are most grateful for the excellent secretarial skills of Lissa Hancock and Joyce Dawson.

This investigation was supported by U. S. Public Health Service grants AM-18243 and AM-19587, and General Clinical Research Center RR95, and the Vanderbilt University Diabetes-Endocrinology Center AM 17026.

Gary L. Mueller is a Major, U. S. Air Force-Medical Corps. The views or opinions expreased or implied are the author's and do not represent those of the U.S. Air Force or any agency of the U. S. Government.

\section{REFERENCES}

1. Madison, L. L., B. Combes, R. Adams, and W. Strickland. 1960. The physiological significance of the secretion 
of insulin into the portal circulation. III. Evidence for a direct immediate effect of insulin on the balance of glucose across the liver. J. Clin. Invest. 39: 507-522.

2. Steele, R., J. S. Bishop, A. Dunn, N. Altszuler, I. Rathgeb, and R. C. De Bodo. 1965. Inhibition by insulin of hepatic glucose production in the normal dog. Am. J. Physiol. 208: 301-306.

3. Chiasson, J. L., J. E. Liljenquist, F. E. Finger, and W. W. Lacy, 1976. Differential sensitivity of glycogenolysis and gluconeogenesis to insulin infusions in dogs. Diabetes. 25: 283-291.

4. Cahill, G. F., Jr. 1971. The physiology of insulin in man. Diabetes. 20: 785-799.

5. Sutherland, E. W. and De Duve, C. 1948. Origin and distribution of hyperglycemic-glycogenolytic factor of the pancreas. J. Biol. Chem. 175: 663-674.

6. Unger, R. H., A. Ohneda, E. Aguilar-Parada, and A. M. Eisentraut. 1969. The role of aminogenic glucagon secretion in blood glucose homeostasis. J. Clin. Invest. 48: 810822.

7. Wahren, J., P. Felig, and L. Hagenfeldt. 1976. Effect of protein ingestion on splanchnic and leg metabolism in normal man and in patients with diabetes mellitus. J. Clin. Invest. 57: 987-999.

8. Brazeau, P., W. Vale, R. Burgus, N. Ling, M. Butcher, J. Rivier, and R. Guillemin. 1973. Hypothalamic peptide that inhibits the secretion of immunoreactive pituitary growth hormone. Science (Wash. D. C.). 179: 77-79.

9. Koerker, D. J., W. Ruch, E. Chideckel, J. Palmer, C. J. Goodner, J. Ensinck, and C. C. Gale. 1974. Somatostatin: Hypothalamic inhibitor of the endocrine pancreas. Science (Wash. D. C.). 184: 482-484.

10. Altszuler, N., B. Gottlieb, and J. Hampshire. 1976. Interaction of somatostatin, glucagon, and insulin on hepatic glucose output in the normal dog. Diabetes. 25: 116121.

11. Cherrington, A. D., J. L. Chiasson, J. E. Liljenquist, A. S. Jennings, U. Keller, and W. W. Lacy. 1976. The role of insulin and glucagon in the regulation of basal glucose production in the postabsorptive dog. J. Clin. Invest. 58: 1407-1418.

12. Chiasson, J. L., J. E. Liljenquist, B. C. SinclairSmith, and W. W. Lacy. 1975. Gluconeogenesis from alanine in normal postabsorptive man. Intrahepatic stimulatory effect of glucagon. Diabetes. 24: 574-584.

13. Andres, R., R. S. Swerdloff, T. Pozefsky, and D. Coleman. 1966. Manual feedback technique for control of blood glucose concentration. In Automation in Analytical Chemistry. L. J. Skeggs, Jr., editor. Mediad, Inc., New York. 486-491.

14. Dillon, R. S. 1965. Importance of the hematocrit in interpretation of blood sugar. Diabetes. 14: 672-674.

15. Aguilar-Parada, E., A. M. Eisentraut, and R. H. Unger. 1969. Pancreatic glucagon secretion in normal and diabetic subjects. Am. J. Med. Sci. 257: 415-419.

16. Wide, L. and J. Porath. 1966. Radioimmunoassay of proteins with the use of Sephadex-coupled antibodies. Biochim. Biophys. Acta. 130: 257-260.

17. Leevy, C. M., C. L. Mendenhall, W. Lesko, and M. M. Howard. 1962. Estimation of hepatic blood flow with indocyanine green. J. Clin. Invest. 41: 1169-1179.

18. Snedecor, G. W. 1956. Statistical methods applied to experiments in agriculture and biology. Iowa State University Press, Ames, Iowa. 5th edition. 35.

19. Blackard, W. G. and N. C. Nelson. 1971. Portal and peripheral vein immunoreactive insulin concentrations following tolbutamide administration. Diabetes. 20: 168170.

20. Krarup, Niels. 1973. The effect of hemorrhage on hepatosplanchnic hemodynamics, liver function and hepatic metabolism. Acta Physiol. Scand. 89: 269-277.

21. Valverde, I., R. Dobbs, and R. H. Unger. 1975. Heterogeneity of plasma glucagon immunoreactivity in normal, depancreatized,and alloxan-diabetic dogs. Metab. Clin. Exp. 24: 1021-1028.

22. Cherrington, A. D., M. D. Caldwell, M. R. Dietz, J. H. Exton, and O. B. Crofford. 1976. The effect of somatostatin on glucose uptake and production by rat tissues in vitro. Diabetes. In press.

23. Gerich, J. E., M. Lorenzi, D. M. Bier, E. Tsalikian, V. Schneider, J. H. Karam, and P. H. Forsham. 1976. Effects of physiologic levels of glucagon and growth hormone on human carbohydrate and lipid metabolism. Studies involving administration of exogenous hormone during suppression of endogenous hormone secretion with somatostatin. J. Clin. Invest. 57: 875-884. 